\title{
DESIGN IMPLEMENTASI KECERDASAAN BUATAN PADA CHATBOT LINE DALAM PERMAINAN TEBAK ANGKA
}

\author{
Hendra Mayatopani ${ }^{1}$, Nurdiana Handayani ${ }^{2}$ \\ ${ }^{1,2}$ Teknik Informatika, Fakultas Teknik Universitas Muhammadiyah Tangerang \\ Jl. Perintis Kemerdekaan 1/33 Cikokol Kota Tangerang \\ TLP. 55793251, 55772949, 55793802, 55736926 \\ E-mail:dra_maya_topani@yahoo.com ${ }^{1}$,dieyan3@gmail.com ${ }^{2}$
}

\begin{abstract}
ABSTRAK
Teknologi Informasi memberikan suatu perubahan yang baru dalam dunia permainan semakin beragam dengan game play yang menyenangkan saat dimainkan dan content diberikan sedemikian menarik dalam pengemasannya, kecerdasan buatan pada game dapat memberikan interaktif selama bermain antara user dan sistem menambah pengalaman bermain, era dunia game telah masuk kedalam aplikasi media sosial beberapa aplikasi yang awalnya terbentuk untuk relationship dan kini menambahkan fitur game yang realtime bermain dengan pertemanan yang telah ditambahkan kedalam aplikasi tersebut. Game yang akan dirancang menggunakan chatbotline pada media sosial Line dimulai dari game play alur tentang menebak suatu angka yang nanti akan keluar apakah hasil tebakan dari user benar atau salah berdasarkan dari kecerdasaan buatan dan yang mendapatkan nilai tertinggi ialah pemenangnya. Hasil yag didapat dari rancangan game memberikan pengalaman user untuk interaksi dalam bermain ataupun dengan user lain meningkatkan keseruan dalam menggunakan media sosial.
\end{abstract}

Kata Kunci: Teknologi Informasi, Kecerdasan buatan, Game play, Media Sosial, Chatbot Line

\begin{abstract}
Information technology provides a new change in the increasingly diverse world of games with play games that are fun when played and content is given in such an interesting way in packaging, artificial intelligence in games can provide interactive play between users and the system adds to the playing experience, the game world has entered Social media applications are some of the applications that were originally formed for relationships and now add realtime gaming features to play with friendships that have been added to the application. The game that will be designed using the chatbotline on social media Line starts from the game play flow about guessing a number that will later come out whether the guess results from the user are correct or wrong based on artificial intelligence and the highest score is the winner. The results obtained from game design provide the user experience for interaction in playing or with other users to increase the excitement in using social media.
\end{abstract}

\section{Keywords: Information Technology, Artificial Intelligence, Game play, Social Media, Chatbot Line}

\section{PENDAHULUAN}

Dunia teknologi membawa segala perubahan dalam kehidupan salah satunya berkomunikasi, pada saat ini teknologi memberikan kemudahan dalam memberikan informasi dalam bentuk digital. Artificial Intelligence (AI) adalah bidang penelitian yang berkembang menampilkan peningkatan jumlah area penelitian penting dan teknologi untuk peningkatan jumlah area aplikasi. Sebagai tambahan untuk inovasi algoritmik, kemajuan pesat dalam AI sering dikaitkan dengan peningkatan daya komputasi karena kemajuan perangkat keras.

AI dapat dialami dalam kehidupan sehari-hari melalui banyak aplikasi praktisnya. AI telah berkembang memungkinkan pemahaman yang lebih baik tentang gambar dan ucapan, deteksi emosi, pencarian web, desain kreatif yang dibantu AI, dan permainan-bermain, di antara banyak tugas lainnya; untuk beberapa mesin tugas ini telah mencapai status pada tingkat manusia atau lebih.

Game merupakan suatu hiburan yang menyenangkan baik itu game yan menggunakan media perangkat game console, komputer, handphone. Banyaknya tipe genre game membuat user menikmati dalam memainkannya dan tampaknya intuitif untuk mengatakan bahwa game strategi adalah permainan yang sangat bergantung pada strategi. Ketika mencoba mendefinisikan genre strategi dalam pembahasannya tentang konsep genre dalam video game, Thomas Apperley menyatakan bahwa game yang bukan game strategi "mungkin masih dimainkan secara strategis" (Apperley, 2006). Game dapat mempengaruhi emosi kepada user menurut (Picard, 1995) pada tulisanya tahun 1995 memperkenalkan istilah Affective Computing dan mendefinisikannya sebagai perhitungan yang menghubungkan timbul atau mempengaruhi emosi. 
Smartphone telah menjadi salah satu kebutuhan manusia dalam hal komunikasi elektronik. Istilah media sosial tersusun dari dua kata, yakni "media" dan "sosial". "Media" diartikan sebagai alat komunikasi (Laughey, 2007; McQuail, 2003). Sedangkan kata "sosial" diartikan sebagai kenyataan sosial bahwa setiap individu melakukan aksi yang memberikan kontribusi kepada masyarakat. Pernyataan ini menegaskan bahwa pada kenyataannya, media dan semua perangkat lunak merupakan "sosial" atau dalam makna bahwa keduanya merupakan produk dari proses sosial (Durkheim dalam Fuchs, 2014).

Chatbots adalah program komputer yang melakukan percakapan melalui teks atau audio, jadi penting untuk memahami cara kerjanya dan caranya anda bisa mendapat manfaat dari mereka, chatbots dengan cepat menjadi salah satu cara paling mudah dan populer bagi perusahaan untuk mulai menggunakan AI ( Rouhiainen, 2018).

line adalah sebuah platform komunikasi yang tidak hanya menawarkan layanan chatting, voice call dan video call. line juga merupakan smart portal dengan beragam solusi terkait konten, hiburan dan bisnis.

\subsection{Rumusan Masalah}

Berdasarkan uraian yang dijelaskan dalam merancang sebuah game yang mudah dimainkan oleh user dan dapat memberikan interaksi melalui media sosial.

1. Bagaimana memberikan sebuah permainan yang berhubungan ke dalam media sosial dan dikemas memudahkan user dalam bermain?

2. Bagaimana peluang user dalam kecerdasan buatan untuk menebak jawaban yang benar?

3. Bagaimana chatbot memberikan interaksi antara user dengan sistem?

\subsection{Batasan Masalah}

Upaya membatasi permasalahan mengenai pembahasan ini agar tidak terlalu luas kepada aspek-aspek relevansi, adalah:

1. Game ini terintegrasi pada aplikasi media sosial line pada chatbotline.

2. Jenis permainan ini adalah teka-teki.

\section{METODE PENELITIAN}

Merumuskan langkah-langkah dalam pembuatan aplikasi yang akan dirancang dengan tahapan sebagai berikut:

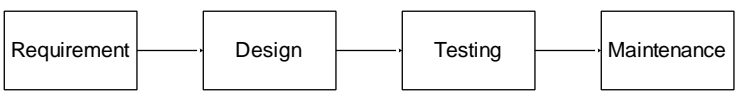

Gambar 1. Proses perancangan.

Pada gambar diagram diatas menjelaskan 4 tahapan proses dalam perancangan berikut penjelasan pada masing-masing proses.

\section{Requiretment}

Tahapan ini menjelaskan proses dari kebutuhan apa saja yang akan dilakukan dalam pembuatan aplikasi sebagai berikut:
a. Media Social Line.
b. Web Server.
c. Messaging API
d. PHP dan Database PostgreSQL

\section{Design}

Pada tahapan ini akan merumuskan alur proses perencanaan sebuah game tebak angka.

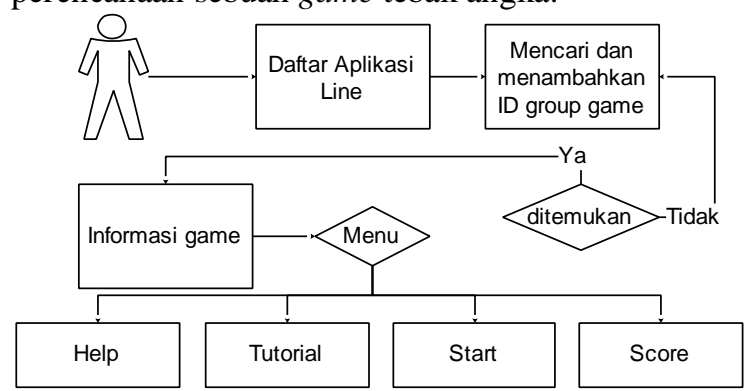

Gambar 2. Proses alur game.

3. Testing

Pada tahapan pengujian sistem aplikasi berdasarakan pengujian kode program apakah masih terdapat bug.

4. Maintenance

Pada tahapan ini akan melakukan perkembangan perubahan game menjadi lebih baik melalui versi pada game.

\subsection{Game Play}

Game play adalah pola yang ditetapkan melalui peraturan dalam permainan, plot, dan hubungan antara pemain dengan permainan di mana pemain mengatasi tantangan dalam game. Berikut game play skenario dibawah ini.

1. Permainan ini diharuskan menambahkan id game pada media sosial line.

2. Untuk dapat bermain dengan user lain tinggal menambahkan dengan mengundang bermain yang terdapat pada menu.

3. User hendaknya membaca instruksi bagaimana cara bermain pada menu.

4. Permainan ini hanya menebak kata yang keluar Kecil atau Besar secara random berdasarkan kecerdasaan buatan.

5. Menampilkan hasil nilai tebakan yang diperoleh oleh user.

6. Permainan memberikan kesenangan dalam bermain.

\section{HASIL DAN PEMBAHASAN}

3.1 Integrasi Media Social LINE

Pada awal tahapan ini untuk dapat menggunakan Messaging API pada line diharuskan melakukan pendaftaran dan konfigurasi LINE channel, sebelum akun LINE@ dapat digunakan, ada beberapa hal 
yang perlu dikonfigurasi. Ada dua halaman yang dapat dikonfigurasi, yaitu pada halaman :
a. LINE@ (https://developers.line.me/)
b. LINE@ Manager (https://admin- official.line.me/).

\subsection{Perancangan Database}

Pada perancangan ini bagaimana membuat database untuk game ini agar data tersimpan dan dapat diolah kembali dibawah ini adalah perancangan database game tebak angka.

\begin{tabular}{|c|c|c|}
\hline score & room & user \\
\hline $\begin{array}{l}\text { id_score (PK) } \\
\text { id_room (FK) } \\
\text { score } \\
\text { date }\end{array}$ & $\begin{array}{l}\text { id_room (PK) } \\
\text { id_line (FK) } \\
\text { date }\end{array}$ & $\begin{array}{l}\text { id_line (PK) } \\
\text { name_line } \\
\text { date }\end{array}$ \\
\hline
\end{tabular}

Gambar 3. Perancangan Database

\subsection{Fugsional Sistem}

Bagian ini merupakan hasil dari beberapa fungsi yang dijalankan pada sistem dalam melakukan sebuah proses game untuk dapat berjalan ketika bermain fungsi tersebut apakah dapat merespon.

a. Fungsi Daftar group

Fungsi ini akan menambahkan ke dalam database user ketika pertama kali seorang user menambahkan game tebak angka kedalam pertemanan terbagi atas 2 yaitu grup dan room.

\$event [ 'source'] [ type']

Pada kode diatas adalah mengambil informasi apakah jenis tersebut grup atau room.

\$idrom = \$event ['source']['roomId'];

Pada kode diatas dpat mengambil info id room.

b. Fungsi Inputan

Tugas dari fungsi ini menvalidasi inputan perkarakter dengan bantuan operator kondisi (IF, ELSE IF, ELSE) jika suatu kata dimasukkan jika kondisi kata tersebut sesuai dengan yang telah ditentukan maka hasilnya akan bernilai true dan sebaliknya jika hasil tersebut tidak sesuai maka akan bernilai false dan jika tidak sesuai dengan kedua nilai tersebut maka akan dikembalikan secara default.

c. Fungsi Nilai

Tugas dari fungsi ini akan menambahkan 1 nilai pada setiap jawaban yang benar dan nilai tersebut akan tersimpan pada database.

Contoh fungsi penambahan nilai: score $+=1$;

pg_query(\$db, "INSERT INTO groups
(id_line, name_line_name, score, id_room,
date) VALUES (DEFAULT, '\$uid', '\$usr', 1,
'\$idrom', CURRENT_DATE);");

\section{d. Fungsi Menu}

Tugas dari fungsi ini merupakan bagian dari menu plihan dalam memulai permainan tebak angka sistem akan mengarahkan jika ada suatu aksi dari user.

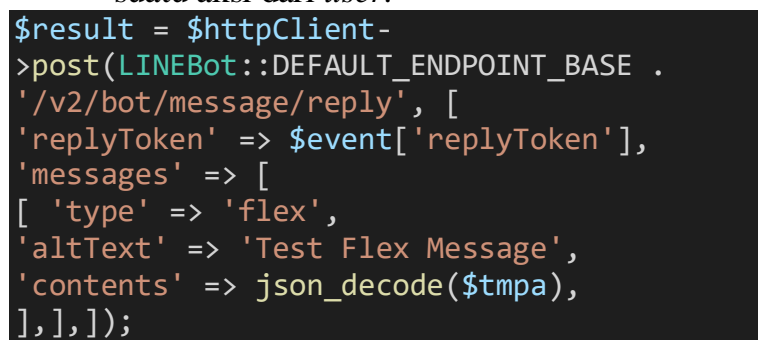

Pada kode diatas akan mengambil tampilan Flex Message merupakan suatu jenis pesan dalam LINE yang mendukung para pengembang untuk dapat mengubah tata letak pesan secara bebas dengan cara mengkombinasikan beberapa jenis pesan menjadi satu pesan sekaligus (dicoding, 2018).

\subsection{Pengujian Aplikasi}

Pada tahapan ini untuk menguji sistem berdasarkan bagaimana tingkat kesulitan dalam menebak angka pada tabel dibawah ini.

Tabel 1. Pengujian Tebak Angka.

\begin{tabular}{|c|c|c|c|}
\hline \multirow{2}{*}{ Total } & \multirow{2}{*}{ Tahap } & \multicolumn{2}{|c|}{ Jawaban } \\
\hline & & Benar & Salah \\
\hline \multirow{3}{*}{10} & 1 & 3 & 7 \\
\hline & 2 & 6 & 4 \\
\hline & 3 & 6 & 4 \\
\hline \multirow{3}{*}{20} & 1 & 8 & 12 \\
\hline & 2 & 6 & 14 \\
\hline & 3 & 11 & 9 \\
\hline \multirow{3}{*}{30} & 1 & 20 & 10 \\
\hline & 2 & 18 & 12 \\
\hline & 3 & 25 & 5 \\
\hline \multirow{3}{*}{40} & 1 & 22 & 18 \\
\hline & 2 & 27 & 13 \\
\hline & 3 & 28 & 12 \\
\hline \multirow{3}{*}{50} & 1 & 35 & 15 \\
\hline & 2 & 42 & 8 \\
\hline & 3 & 17 & 33 \\
\hline \multicolumn{2}{|c|}{ Rata-Rata } & 18 & 12 \\
\hline
\end{tabular}

\subsection{Antarmuka Sistem}

Hasil dari perancangan ini menjelaskan penggambaran dari game tebak angka bagaimana alur proses bagi seorang user untuk mengetahui game yang dimainkan dan menghasilka sebuah game yang user friendly. 


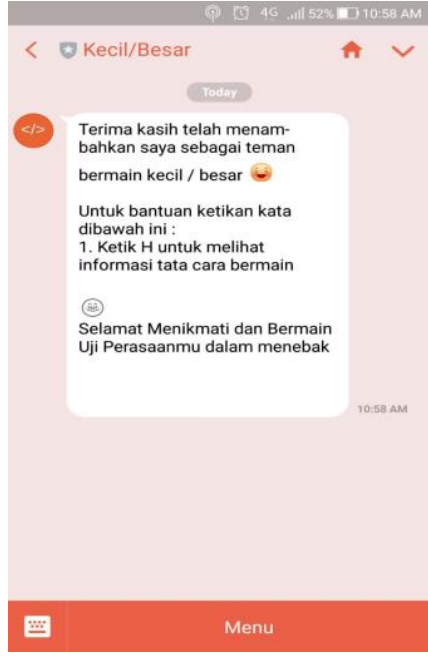

Gambar 3. Proses Menambahkan Id game.

Keterangan gambar diatas merupakan informasi bahwa user telah menambahkan permainan ini kedalam aplikasi chatbotline dan di respon oleh aplikasi bahwa user telah bergabung dalam permainan.

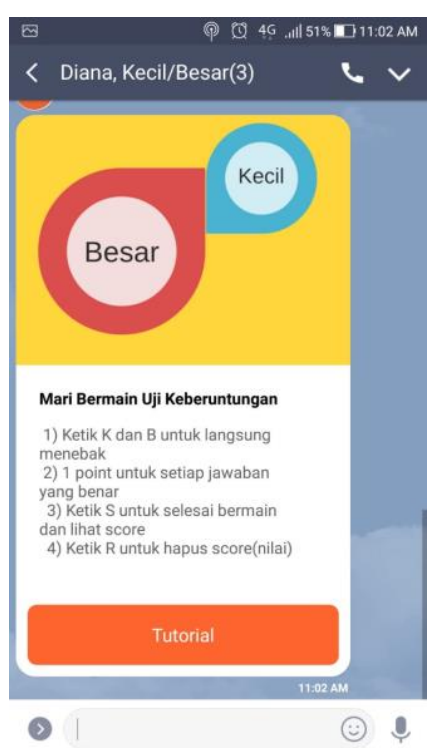

Gambar 4. Proses Info game.

Keterangan diatas mengenai informasi flex message mengenai permainan tebak angka berikut :

a. Ketik K dan B langsung menebak angka.

b. 1 point untuk setiap jawaban yang benar.

c. Ketik S untuk selesai permainan.

d. Ketik R utuk menghapus nilai memulai dari awal permainan.

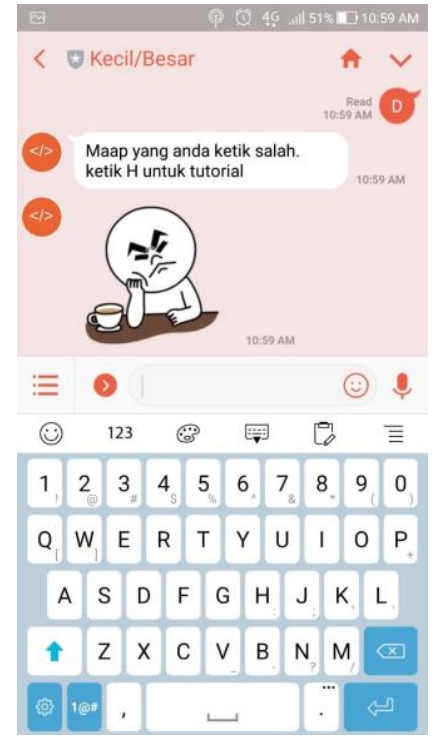

Gambar 5. Input Kata Salah.

Keterangan gambar diatas mengenai informasi kata ketikan yang salah digunakan salah dibawah ini adalah kodenya.

\section{\$textMessageBuilder 1 = new \\ TextMessageBuilder('Maap yang anda ketik \\ salah. ketik H untuk tutorial'); \\ $\$$ stickerMessageBuilder = new \\ StickerMessageBuilder (1, 101);}

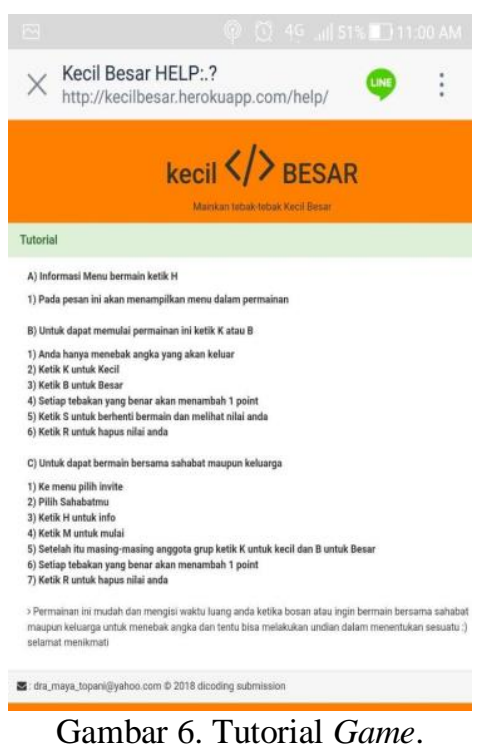

Keterangan gambar diatas mengenai informasi dari tutorial permainan bagaimana permainan dimulai berikut kode dibawah ini.

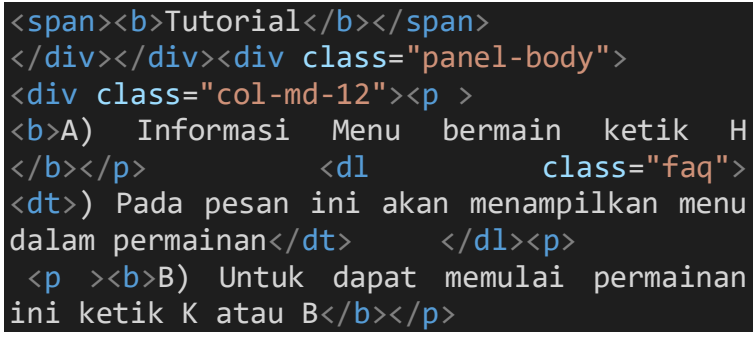



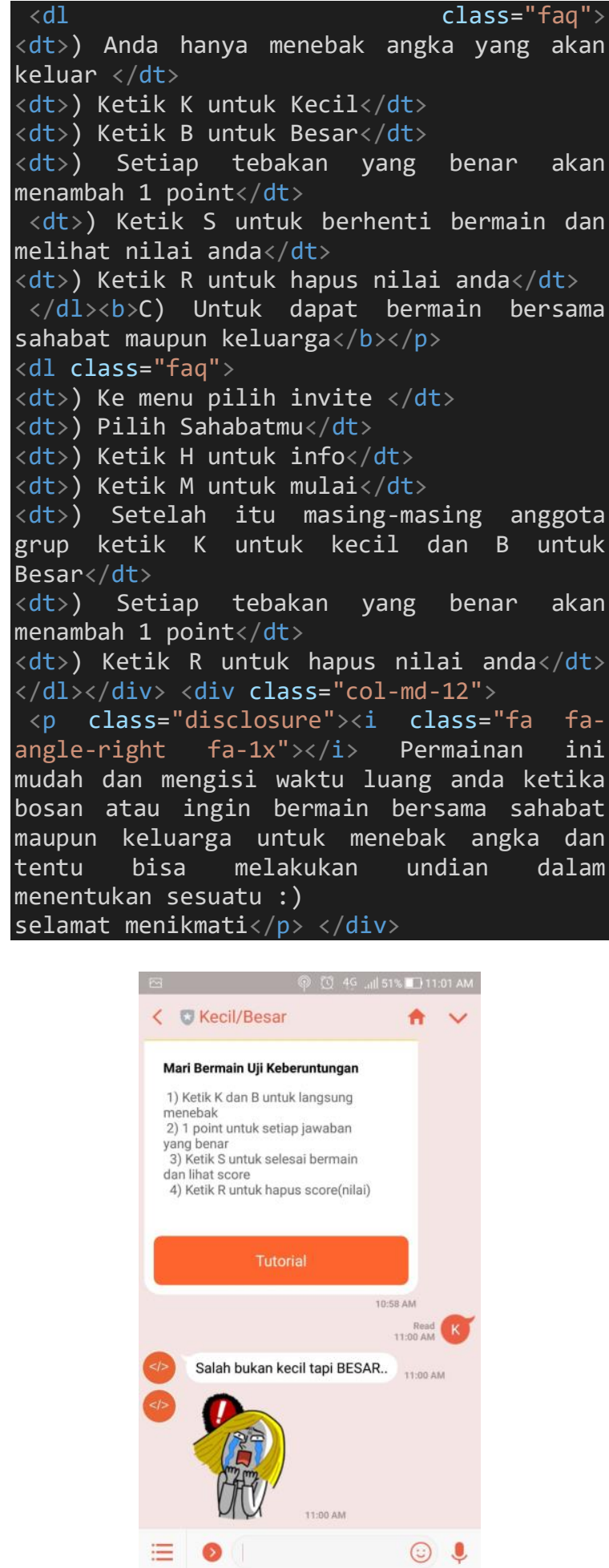

Gambar 7. Jawaban Salah.

Pada keterangan gambar diatas merupakan hasil dari jawaban yang salah berikut kode dibawah ini. \$textMessageBuilder1 = new TextMessageBuilder('Salah bukan kecil tapi BESAR. . ');

\$stickerMessageBuilder = new

StickerMessageBuilder (1, 123);

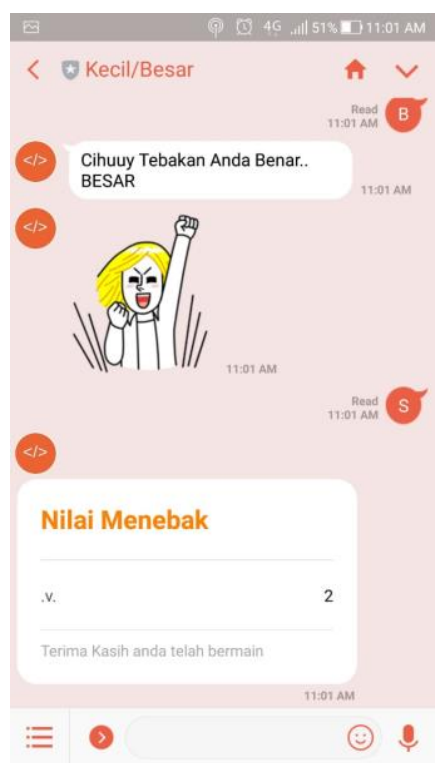

Gambar 7. Jawaban Benar dan Nilai Score.

Pada keterangan gambar diatas merupakan hasil dari jawaban yang Benar berikut kode dibawah ini.

\$textMessageBuilder1 = new
TextMessageBuilder('Cihuuy Tebakan Anda Benar..
Kecil');
\$stickerMessageBuilder = new StickerMessageBuilder(1,
138);

\section{KESIMPULAN}

Dari hasil yang telah didapatkan pada permainan kecerdasaan buatan dalam chatbotline tebak angka ada beberapa kesimpulan sebagai berikut.

1. Permainan ini hanya menebak angka dan tingkat kesulitan berdasarkan dari pengujian bahwa rata-rata dalam menebak angka untuk seorang user menentukan jawaban yang benar tidak terlalu susah dan tidak terlalu mudah untuk mendapatkan hasil yang sempurna.

2. Untuk dapat memulai permainan ini, hanya bisa dimainkan jika mempunyai aplikasi media sosial LINE dan seorang user mempunyai akun media sosial LINE.

3. Chatbotline pada permainan ini memberikan kemudahan dalam informasi percakapan satu atau lebih dengan menggunakan text.

\section{PUSTAKA}

Apperley, T. H. (2006). Genre and game studies: Toward a critical approach to video game genres. Simulation and Gaming, 37, pp. 6-23.

Dicoding (2018). Belajar Membangun chatbot Line www.dicoding.com/academies/32/tutorials.

Freeman, D.: Creating emotion in games: The craft and art of emotioneering ${ }^{\mathrm{TM}}$. Comput. Entertain. 2(3), 1515 (Jul 2004).

Fuchs, C. (2014). Social media a critical introduction. Los Angeles: SAGE Publication, Ltd. 
Laughey, D. (2007). Themes in media theory. New York: Open University Press.

McQuail, D. (2003). Teori komunikasi massa. Jakarta: Penerbit Erlangga.

Picard, R.W.: A ective computing. MIT Media Laboratory (1995).

Rouhiainen, Lasse (2018) Artificial Intelligence 101 Things You Must Know Today About Our Future. 